\title{
Short stature due to GHSR deficiency
}

\author{
INSERM
}

\section{Source}

INSERM. (1999). Orphanet: an online rare disease and orphan drug data base. Short stature due to GHSR deficiency. ORPHA:314811

Short stature due to GHSR deficiency is a rare, genetic, endocrine growth disease, resulting from growth hormone secretagogue receptor (GHSR) deficiency, characterized by postnatal growth delay that results in short stature (less than -2 SD). The pituitary gland is typically without morphological changes, although anterior pituitary gland hypoplasia has been reported. 